\title{
UTILIZAÇÃO DE CONCENTRADO PROTÉICO DE SORO EM UM PRODUTO “TIPO PÃO DE QUEIJO”
}

\section{USE OF WHEY PROTEIN CONCENTRATE IN PRODUCT TYPE "CHEESE BREAD"}

\author{
Francy Zambrano ${ }^{1}$, Marina Costa da Silva ${ }^{2}$, Rita de Cássia Celeste Ormenese ${ }^{3}$ \\ ${ }^{1}$ Universidade Federal do Triângulo Mineiro-UFTM-Uberaba, Brasil, francyzambrano@ hotmail.com \\ ${ }^{2}$ Universidade Estadual de Campinas, Campinas, Brasil marinacsilva@ gmail.com \\ ${ }^{3}$ Instituto de Tecnologia de Alimentos-ITAL-Campinas, Brasil, ritaorm@ital.sp.gov.br
}

\begin{abstract}
Resumo
O objetivo deste trabalho foi avaliar o efeito da utilização de concentrado proteico de soro (CPS) como substituto parcial de queijo em um produto tipo pão de queijo (PTPQ). A adição de CPS foi avaliada sensorialmente através da aparência, aparência da casca, textura, sabor e avaliação geral. Também foi determinado o volume específico pelo método de deslocamento de sementes e a textura em texturômetro TA-XT2i. Foi realizada análise de variância (ANOVA) e teste de Tukey ao nível de $5 \%$ de significância utilizando o programa estatístico SAS (Statistical Analysis System, versão 8.0 - The SAS Institute, Cary, N.C.). A substituição de queijo e o tempo de estocagem ocasionaram efeito significativo $(p<0,05)$ em todas as características avaliadas no PTPQSE exceto com relação ao sabor. Foi possível obter um produto tipo pão de queijo escaldado (PTPQE) estocado durante 2 meses utilizando concentrado proteico de soro (CPS) como substituto parcial (25\%) de queijo sem ocasionar diferenças significativas nas características sensoriais avaliadas $e$ com melhor volume específico com relação ao padrão.
\end{abstract}

Palavras-chave: produtos de panificação; subprodutos industriais; $\beta$-lactoglobulina, $\alpha$ lactoalbumina; avaliação sensorial.

\section{Introdução}

A atenção dos pesquisadores em estudos sobre a utilização de proteínas como ingredientes funcionais é crescente, a exemplo disso, existem no mercado internacional produtos lácteos comerciais e ingredientes com apelo funcional baseado em peptídeos bioativos obtidos das proteínas do leite (caseínas e soroproteínas). Em muitos casos é possível, ao empregar as proteínas como agentes funcionais, desenvolver produtos com características especiais e agregar valor a subprodutos os quais em geral representam um problema para as indústrias.

Cerca de 90 a 95\% do volume do leite usado para a fabricação de queijos resultam em soro, contendo cerca de $0,8 \%$ de proteínas este subproduto é muito rico em água e lactose ( $94 \%$ e 4,5\%, 
respectivamente), por isso os custos com tecnologia para concentrá-lo, especialmente por ultrafiltração, são elevados (ANTUNES, 2004).

O soro de leite vem despertando o interesse de inúmeros pesquisadores em todo o mundo devido à sua potencialidade nutricional, funcional e econômica.

Sob o ponto de vista nutricional, o soro de leite é considerado levemente superior comparado à caseína, que possui quantidade limitada dos aminoácidos sulfurados (metionina e cistina), além de ter alto conteúdo dos aminoácidos essenciais, especialmente lisina, treonina, triptofano, fenilalanina e tirosina e a presença da proteína superior lactoalbumina. A qualidade nutricional de uma proteína depende do padrão e concentração de aminoácidos essenciais, aqueles que o organismo humano não consegue sintetizar (OLIVEIRA et al., 2012).

Sgarbieri (2005) cita que concentrados de proteínas do soro de leite bovino apresentaram propriedades funcionais com atividades anticancerígenas em modelos animais e em culturas de células cancerígenas, antibacteriana e antiviral, antiúlcera e maior proteção ao sistema cardiovascular. As proteínas do soro também apresentam poder imunomodulador, ajudam no controle da pressão sanguínea e agem como agente redutor do risco cardíaco. O soro de leite já foi chamado de "soro da memória" pelo fato desse subproduto concentrar componentes que atuam sobre os neurônios na formação de suas redes e das sinapses (OLIVEIRA et al., 2012).

Como resultado da utilização integral do soro de leite, tem-se conseguido a redução da poluição ambiental, pois o soro de leite é muito poluidor, devido a sua alta demanda biológica de oxigênio (ANTUNES et al., 2004).

As proteínas do soro são utilizadas em diversos produtos alimentícios como leite desproteinizado, queijos, ricota, doce de leite, bebidas lácteas entre outros, pelo seu alto valor nutricional e por conferir excelentes propriedades funcionais, nutricionais e aromáticas. Vendas adicionais de produtos como concentrado proteico de soro (CPS), creme de soro, lactose, minerais do leite, além de outros novos produtos a base de soro de leite, como a obtenção de filmes transparentes comestíveis utilizando isolado proteico são obtidos através do aproveitamento das proteínas do soro (OLIVEIRA et al., 2012).

Os CPS são sistemas multifuncionais que vêm sendo adicionados a diversos alimentos com o objetivo de modificar propriedades através de gelatinização, aumento de viscosidade, estabilização de emulsões ou espumas, entre outros (ANTUNES et al., 2003).

As propriedades gelificantes e emulsificantes tem permitido utilizar CPS como substitutos de gordura em produtos de baixas calorias (BORGES, 2000). Além dessas duas propriedades os CPS podem proporcionar aos sistemas alimentares diversos atributos que são prováveis tenham ajudado a substituir parcialmente algumas características funcionais e tecnológicas do queijo nas formulações avaliadas. Dentre estes atributos os mais relacionados com este estudo são: prover 
textura e estrutura para produtos de panificação e confeitaria e elasticidade, coesão e adesão para estruturas alimentares, viscosidade, estabilidade e estrutura para géis e habilidade de coagular. Os CPS também funcionam como surfactantes na estabilização de emulsões e possuem adequada estabilidade ao aquecimento (MAISTRO, 1999). Esses produtos também se destacam pela sua solubilidade em toda a extensão de $\mathrm{pH}$, capacidade de incorporar ar e de absorção de água.

Alguns estudos avaliaram os CPS Simplesse e/ou Dairy-Lo em iogurte (McMAHON et al., 1996; YAZICI e AKGUN, 2004; ANTUNES et al., 2004; SANDOVAL-CASTILLA et al., 2004), bebidas lácteas (SIVIERI e OLIVEIRA, 2002) e produtos de panificação (O'BRIEN et al., 2003; BENASSI et al., 2001; ESTELLER e LANNES, 2005; CLARETO et al., 2006; ZAMBRANO et al., 2012). Os últimos autores avaliaram a substituição de gordura em pão de queijo produzido por dois métodos industriais de fabricação utilizando Dairy-Lo. No entanto, não foi ainda estudada a utilização de CPS como substituto de queijo em um produto Tipo pão de queijo.

Segundo Minim et al., (2000) o pão de queijo, produto tradicionalmente do estado de Minas Gerais, hoje largamente consumido no Brasil, não possui Padrão de Identidade e Qualidade que defina tecnologia de produção, caracterização ou tipificação do produto. Por isso, sob a denominação de "pão de queijo" podem ser encontrados no mercado diferentes tipos de produtos (SANTOS, 2006). A pesar da grande maioria dos produtores de pão de queijo a nível industrial utilizar o método tradicional de escaldamento e como matérias-primas fécula e/ou polvilho, óleo, água e/ou o leite, ovos e queijo (PIROZI e CANAVESI, 1998) podem também ser utilizados diversos ingredientes como batata e algumas farinhas. Quanto ao processo, industrialmente também é fabricado pão de queijo com amido modificado, pré-gelatinizado, visando a substituição da etapa de escaldamento.

A maioria dos produtores industriais de pão de queijo utilizam uma mistura de queijo minas padrão e parmesão. Dessas matérias-primas o queijo é a mais cara e em algumas épocas do ano falta ou se torna escasso devido à estacionalidade na produção de leite aumentando ainda mais o seu preço no mercado regional. Além disso, existe muita dificuldade na padronização da qualidade microbiológica do queijo Minas Padrão.

O objetivo deste trabalho foi avaliar o efeito da utilização de $\operatorname{ALACEN}^{\mathrm{TM}} 392$, concentrado proteico de soro (CPS) como substituto parcial de queijo em um produto tipo pão de queijo (PTPQ) elaborado através dos dois processos tecnológicos utilizados pela indústria, o tradicional que utiliza escaldamento e o não tradicional realizado a frio.

\section{Material e métodos}


As matérias primas utilizadas foram fécula de mandioca (Pinduca), polvilho azedo (Pinduca), amido modificado National 75 (National Starch), o concentrado protéico de soro (CPS) ALACEN $^{\mathrm{TM}} 392$ (New Zealand - Brasil) e aroma de queijo SF 18793 (Sun Foods). Foram também utilizados queijo tipo minas padrão, leite integral, ovos in natura, óleo e sal comprados no mercado local.

Os equipamentos utilizados no processo de fabricação de pão de queijo foram: batedeira planetária (Kitchen AID, modelo e série: K5SS); multiprocessador (Braun do Brasil tipo: MC-1); forno Elétrico (J. Ryal \& Cia); balança semi-analítica; freezer Horizontal (Metalfrio) e analisador de textura (Stable Micro Systems, TA-XT2i).

Na elaboração dos pães de queijo os níveis de adição de CPS nas formulações padrão de pão de queijo foram realizados com base nos resultados de Zambrano et al., (2009), utilizando dois processos de fabricação. No primeiro, foi realizado escaldamento da fécula de mandioca e do polvilho azedo com uma mistura de óleo e água/leite fervente. No segundo, a mistura dos ingredientes foi realizada a frio, sem escaldamento e adicionado o amido modificado National 75.

A Tabela 1 apresenta as formulações padrão do pão de queijo escaldado (PQE) e pão de queijo sem escaldamento (PQSE).

Tabela 1 - Formulações padrão de pão de PQE e PQSE

\begin{tabular}{lcc}
\hline \multicolumn{1}{c}{ Ingrediente } & & $\mathbf{( \% )}$ \\
\cline { 2 - 3 } & PQE & PQSE \\
\hline Fécula de mandioca & 34,00 & 28,31 \\
Polvilho & 4,73 & - \\
Amido modificado National 75 & - & 8,82 \\
Queijo minas padrão & 16,93 & 22,1 \\
Ovo integral & 9,00 & 17,17 \\
Óleo & 9,5 & - \\
Gordura vegetal hidrogenada & - & 6,33 \\
Água & 15,44 & 13,93 \\
Leite liquida integral & 9,00 & - \\
Leite em pó desnatado & - & 2,0 \\
Sal & 1,4 & 1,34 \\
\hline Total & 100 & 100 \\
\hline
\end{tabular}

Algumas variações nas formulações do produto tipo pão de queijo escaldado (PTPQE) e sem escaldamento (PTPQSE) foram necessárias nos testes de substituição. As porcentagens de acréscimo (+) ou diminuição (-) da Tabela 2 são expressas em relação às formulações padrão (Tabela 1). Nas formulações com substituição de queijo o ovo foi diminuído para melhorar a consistência da massa na etapa de modelagem.

Para o preparo das amostras escaldadas, os ingredientes secos (fécula e polvilho) foram homogeneizados durante 3 minutos. A seguir o óleo, a água e o leite foram aquecidos até temperatura de ebulição e mantidos nesta temperatura durante 2 minutos. A mistura de óleo, água e 
leite quente foi adicionada sobre a fécula e o polvilho, previamente homogeneizados e misturados durante 1 minuto. Na seqüência, o sal previamente dissolvido no ovo e o queijo foram adicionados e misturados durante 3 minutos. Toda a mistura foi realizada na velocidade baixa.

Tabela 2 - Adaptações das formulações com e sem escaldamento com substituição de queijo *

\begin{tabular}{|c|c|c|c|}
\hline \multirow{3}{*}{ Ingrediente } & \multicolumn{3}{|c|}{ Nível de substituição (\%) } \\
\hline & \multicolumn{2}{|c|}{25} & \multirow{2}{*}{$\begin{array}{c}50 \\
\text { PTPQSE }\end{array}$} \\
\hline & PTPQE & PTPQSE & \\
\hline Queijo minas padrão* & -25 & -25 & -50 \\
\hline Ovo integral* & -39 & & \\
\hline Água* & & -28 & -32 \\
\hline ALACEN $^{\mathrm{TM}} 392$ ** & +8 & +8 & +17 \\
\hline Aroma SF $18793^{* *}$ & $+0,6$ & $+0,6$ & 1,3 \\
\hline
\end{tabular}

No preparo amostras sem escaldadamento os ingredientes secos (fécula de mandioca, amido modificado e leite em pó) foram misturados por 5 minutos na velocidade mais baixa do equipamento. A seguir foi adicionada e misturada a gordura vegetal hidrogenada, na mesma velocidade, durante 5 minutos. Na sequiência, foi incorporado o sal previamente dissolvido no ovo e misturado na velocidade 2 durante 1 minuto. O queijo previamente ralado foi adicionado e misturado por 1 minuto e finalmente a água por mais 5 minutos, na mesma velocidade.

Nos testes de substituição nas formulações com e sem escaldamento o CPS foi misturado junto com os ingredientes secos. Conforme orientação dos fabricantes e resultados de Zambrano et al. (2009) a substituição foi realizada na proporção de 3:1 (gordura:CPS).

Todas as amostras foram moldadas e pesadas (25 a $26 \mathrm{~g}$ ) manualmente e assadas entre $170^{\circ} \mathrm{C}$ a $190^{\circ} \mathrm{C}$ durante 29 minutos. Nos primeiros 15 minutos a chave superior do forno permaneceu desligada e a chave inferior ligada no nível médio, nos últimos 14 minutos as duas chaves permaneceram ligadas neste nível.

Todas as amostras foram analisadas quanto a características sensoriais, volume específico e textura. As amostras escaldadas foram avaliadas durante 4 e as não escaldadas por 5 períodos. Os períodos $0,1,2,3$ e 4 foram considerados 1, 30, 60, 90 e 120 dias, respectivamente, após a elaboração das amostras.

As amostras escaldadas foram analisadas por 3 meses e as não escaldadas durante 4 meses de estocagem.

Todas as amostras foram congeladas, embaladas em polietileno de baixa densidade e estocadas em freezer horizontal a $-15^{\circ} \mathrm{C}$, inclusive as avaliadas no período zero (1 dia de estocagem).

As características sensoriais de aparência, aparência da casca, textura e sabor das amostras foram avaliadas por uma equipe composta por 5 especialistas em tecnologia de fabricação de pão de 
queijo e técnicos da área com grande conhecimento sobre as características adequadas para um pão de queijo de qualidade. Além disso, os 5 provadores foram selecionados quanto à acuidade sensorial, de acordo com a norma ISO-8586-1 (1993). Essa equipe definiu, em conjunto, os atributos que deveriam ser avaliados, as escalas empregadas para cada atributo com termos característicos de pão de queijo de baixa e de elevada qualidade. Isto permitiu ainda avaliar cada amostra de forma global, levando em consideração o quanto cada uma delas se aproximava ou não de um produto completamente característico. Foi empregada uma escala estruturada em que os pontos 1 e 5 foram definidos conforme descrito a seguir: aparência (1. nota mínima - pouco atraente: falta de cor, muitas estrias e assimétrico e 5. nota máxima - muito atraente: boa cor, sem estrias e simétrico); aparência da casca (1. nota mínima - casca muito grossa e esfarinhenta e 5. nota máxima - casca nem muito fina e nem muito grossa e não esfarinhenta); textura (1. nota mínima - nenhuma maciez, precisa realizar muito esforço para morder e mastigar e 5. nota máxima - muito macio, é preciso realizar pouco esforço para morder e mastigar); sabor (1. nota mínima nenhum sabor de queijo ou sabor desagradável e 5. nota máxima - muito sabor de queijo ou sabor agradável); avaliação global (1. produto pouco característico e 5. produto completamente característico).

$\mathrm{Na}$ análise de textura foi avaliada a força em compressão, expressa em grama-força (gf), utilizando Texturômetro TA-XT2i (probe cilíndrico de alumínio P36R, velocidade pré-teste 1,0 $\mathrm{mm} / \mathrm{s}$, velocidade teste $1,7 \mathrm{~mm} / \mathrm{s}$ e velocidade pós-teste $10,0 \mathrm{~mm} / \mathrm{s}$, distância 40,0\% e trigger $5,0 \mathrm{~g}$ ) (STABLE MICRO SYSTEMS, 1997).

Para cada avaliação de textura foram feitas 6 replicas (unidades).

$\mathrm{O}$ volume específico das amostras, expresso em $\mathrm{cm}^{3} \cdot \mathrm{g}^{-1}$, foi calculado pela relação entre o volume de 3 unidades de pão de queijo $\left(\mathrm{cm}^{3}\right)$, determinado pelo método de deslocamento de sementes e o seu peso (g ) (ZAMBRANO et. al., 2009).

Na análise estatística os resultados da avaliação sensorial (aparência, aparência da casca, textura, sabor, avaliação global), volume específico e textura instrumental de todas as amostras, foram submetidos à análise de variância e teste de Tukey. Foi realizada comparação das amostras dentro de cada época (linha), e durante o período de estocagem (coluna) ao nível de significância de 5\% através do programa SAS (Statistical Analysis System, versão 8.0 - The SAS Institute, Cary, N.C.).

Foram realizadas comparações entre as médias em dois conjuntos de dados: o primeiro com as amostras escaldadas e o segundo com as sem escaldadamento. Para cada tipo de processamento foi utilizado um padrão (Tabela 1). 


\section{Resultados e discussão}

Nas Tabelas 3 e 4 são apresentados os resultados da avaliação das características sensoriais e físicas das amostras escaldadas e sem escaldamento, respectivamente.

Tabela 3 - Características sensoriais e físicas das amostras escaldadas

\begin{tabular}{|c|c|c|c|}
\hline \multirow{6}{*}{ } & \multirow[b]{2}{*}{ Tempo (meses) } & \multicolumn{2}{|c|}{ Nível de substituição (\%) } \\
\hline & & $\mathbf{0}$ & 25 \\
\hline & $\mathbf{0}$ & $3.9 \pm 0.7$ a A & $4.0 \pm 0.9$ a $\mathrm{A}$ \\
\hline & 1 & $3.8 \pm 1.1 \mathrm{a} \mathrm{A}$ & $3.7 \pm 1.2 \mathrm{a} \mathrm{A}$ \\
\hline & 2 & $3.7 \pm 0.8$ a A & $3.5 \pm 0.9$ a $\mathrm{A}$ \\
\hline & 3 & $3.8 \pm 0.8$ a A & $3.9 \pm 0.5$ a A \\
\hline \multirow{6}{*}{ 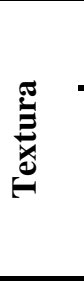 } & & \multicolumn{2}{|c|}{ Nível de substituição (\%) } \\
\hline & Tempo (meses) & $\mathbf{0}$ & 25 \\
\hline & $\mathbf{0}$ & $4.7 \pm 0.4$ a A & $3.7 \pm 1.3 \mathrm{a} \mathrm{A}$ \\
\hline & 1 & $3.5 \pm 0.5$ a A & $3.5 \pm 1.0 \mathrm{a} \mathrm{A}$ \\
\hline & 2 & $3.9 \pm 0.9$ a $\mathrm{A}$ & $3.6 \pm 0.9 \mathrm{a} \mathrm{A}$ \\
\hline & 3 & $3.7 \pm 1.0 \mathrm{a} \mathrm{A}$ & $4.1 \pm 0.8 \mathrm{a} \mathrm{A}$ \\
\hline \multirow{6}{*}{ 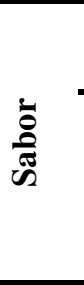 } & & \multicolumn{2}{|c|}{ Nível de substituição (\%) } \\
\hline & Tempo (meses) & $\mathbf{0}$ & 25 \\
\hline & $\mathbf{0}$ & $4.0 \pm 0.7$ a $A$ & $2.8 \pm 1.3 \mathrm{a} \mathrm{A}$ \\
\hline & 1 & $3.7 \pm 0.7$ a A & $3.8 \pm 0.6$ a A \\
\hline & 2 & $3.7 \pm 1.0 \mathrm{a} \mathrm{A}$ & $3.7 \pm 1.0 \mathrm{a} \mathrm{A}$ \\
\hline & 3 & $2.9 \pm 1.2 \mathrm{a} \mathrm{A}$ & $3.8 \pm 1.0 \mathrm{a} \mathrm{A}$ \\
\hline \multirow{6}{*}{ 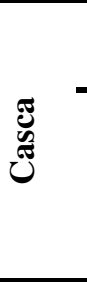 } & & \multicolumn{2}{|c|}{ Nível de substituição (\%) } \\
\hline & Tempo (meses) & $\mathbf{0}$ & 25 \\
\hline & $\mathbf{0}$ & $4.3 \pm 0.4$ a A & $3.8 \pm 1.1 \mathrm{a} \mathrm{A}$ \\
\hline & 1 & $3.7 \pm 0.8$ a $\mathrm{A}$ & $3.2 \pm 1.1 \mathrm{a} \mathrm{A}$ \\
\hline & 2 & $3.8 \pm 0.8$ a A & $3.4 \pm 0.9$ a A \\
\hline & 3 & $3.5 \pm 1.6 \mathrm{a} \mathrm{A}$ & $4.0 \pm 0.6 \mathrm{a} \mathrm{A}$ \\
\hline \multirow{6}{*}{ 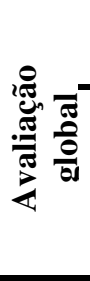 } & & \multicolumn{2}{|c|}{ Nível de substituição (\%) } \\
\hline & Tempo (meses) & $\mathbf{0}$ & 25 \\
\hline & $\mathbf{0}$ & $4.3 \pm 0.4$ a $\mathrm{A}$ & $3.5 \pm 1.0 \mathrm{a} \mathrm{A}$ \\
\hline & 1 & $3.5 \pm 0.5$ a A & $3.5 \pm 0.7$ a A \\
\hline & 2 & $3.7 \pm 0.7$ a $\mathrm{A}$ & $3.5 \pm 0.9$ a $\mathrm{A}$ \\
\hline & 3 & $3.2 \pm 1.0 \mathrm{~b} \mathrm{~A}$ & $4.1 \pm 0.4 \mathrm{a} \mathrm{A}$ \\
\hline \multirow{6}{*}{ 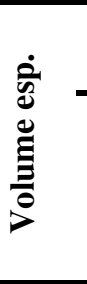 } & & \multicolumn{2}{|c|}{ Nível de substituição (\%) } \\
\hline & Tempo (meses) & $\mathbf{0}$ & 25 \\
\hline & $\mathbf{0}$ & $39.80 \pm 0.67 \mathrm{~b} \mathrm{~A}$ & $33.60 \pm 2.43$ a B \\
\hline & 1 & $36.70 \pm 1.72$ a B & $37.50 \pm 1.87 \mathrm{a} A$ \\
\hline & 2 & $32.40 \pm 1.19$ a C & $33.00 \pm 2.12 \mathrm{a} \mathrm{B}$ \\
\hline & 3 & $32.70 \pm 1.92$ a C & $35.20 \pm 1.44 \mathrm{~b} \mathrm{AB}$ \\
\hline \multirow{6}{*}{ 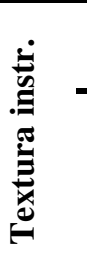 } & & \multicolumn{2}{|c|}{ Nível de substituição (\%) } \\
\hline & Tempo (meses) & $\mathbf{0}$ & 25 \\
\hline & $\mathbf{0}$ & $1018.53 \pm 248.653534$ b B & $1788.34 \pm 410.4532$ a A \\
\hline & 1 & $1471.44 \pm 437.8335873$ a A & $1713.82 \pm 151.7188$ a A \\
\hline & 2 & $1575.53 \pm 282.5731201 \mathrm{a} \mathrm{A}$ & $1320.65 \pm 258.5544 \mathrm{~b} \mathrm{~B}$ \\
\hline & 3 & $1039.03 \pm 137.395745$ b B & $1877.89 \pm 359.4131 \mathrm{a} \mathrm{A}$ \\
\hline
\end{tabular}

As amostras (média \pm desvio padrão) seguidas de mesmas letras minúsculas na linha não diferem ao nível de $5 \%$.

As amostras (média \pm desvio padrão) seguidas de mesmas letras maiúsculas na coluna não diferem ao nível de $5 \%$

As letras minúsculas na LINHA testa se há diferenças significativas entre as amostras dentro de cada época

As letras maiúsculas na COLUNA testa se houve diferenças durante o período de estocagem para cada amostra. 
Tabela 4 - Características sensoriais e físicas das amostras sem escaldadamento

\begin{tabular}{|c|c|c|c|c|}
\hline \multirow{7}{*}{ 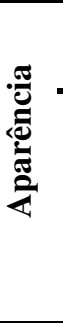 } & \multirow[b]{2}{*}{ Tempo (meses) } & \multicolumn{3}{|c|}{ Nível de substituição (\%) } \\
\hline & & $\mathbf{0}$ & 25 & 50 \\
\hline & $\mathbf{0}$ & $4.4 \pm 0.9$ a A & $3.8 \pm 1.0 \mathrm{~b} \mathrm{~A}$ & $3.5 \pm 0.7 \mathrm{~b} \mathrm{~A}$ \\
\hline & 1 & $4.1 \pm 0.7$ a A & $2.8 \pm 1.2 \mathrm{~b} \mathrm{~A}$ & $3.1 \pm 0.9 \mathrm{~b} \mathrm{~A}$ \\
\hline & 2 & $4.3 \pm 0.4 \mathrm{a} \mathrm{A}$ & $3.6 \pm 0.9 \mathrm{ab} A$ & $3.2 \pm 0.8 \mathrm{~b} \mathrm{~A}$ \\
\hline & 3 & $3.8 \pm 0.9$ a A & $2.7 \pm 1.5 \mathrm{ab} \mathrm{A}$ & $2.7 \pm 0.8 \mathrm{~b} \mathrm{~A}$ \\
\hline & 4 & $3.6 \pm 0.6 \mathrm{a} \mathrm{A}$ & $3.2 \pm 0.9 \mathrm{ab} \mathrm{A}$ & $2.8 \pm 0.8 \mathrm{~b} \mathrm{~A}$ \\
\hline \multirow{7}{*}{ 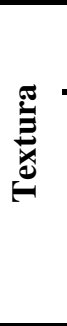 } & & \multicolumn{3}{|c|}{ Nível de substituição (\%) } \\
\hline & Tempo (meses) & $\mathbf{0}$ & 25 & 50 \\
\hline & $\mathbf{0}$ & $4.1 \pm 1.2 \mathrm{a} \mathrm{A}$ & $4.0 \pm 1.3 \mathrm{a} \mathrm{A}$ & $3.1 \pm 0.7$ a A \\
\hline & 1 & $3.8 \pm 1.0 \mathrm{a} \mathrm{A}$ & $3.2 \pm 1.2 \mathrm{a} \mathrm{A}$ & $3.5 \pm 1.0 \mathrm{a} \mathrm{A}$ \\
\hline & 2 & $4.4 \pm 0.7$ a A & $3.5 \pm 0.9$ a A & $3.5 \pm 1.4 \mathrm{a} \mathrm{A}$ \\
\hline & 3 & $4.4 \pm 0.7$ a A & $3.5 \pm 1.0 \mathrm{ab} \mathrm{A}$ & $3.0 \pm 1.0 \mathrm{~b} \mathrm{~A}$ \\
\hline & 4 & $4.3 \pm 0.5$ a A & $3.4 \pm 1.3 \mathrm{ab} \mathrm{A}$ & $3.1 \pm 1.3 \mathrm{~b} \mathrm{~A}$ \\
\hline \multirow{7}{*}{$\begin{array}{l}\grave{8} \\
\frac{\hat{\sigma}}{\pi}\end{array}$} & & \multicolumn{3}{|c|}{ Nível de substituição (\%) } \\
\hline & Tempo (meses) & $\mathbf{0}$ & 25 & 50 \\
\hline & $\mathbf{0}$ & $4.0 \pm 0.7$ a $\mathrm{A}$ & $3.8 \pm 1.0 \mathrm{a} \mathrm{A}$ & $3.5 \pm 0.7$ a A \\
\hline & 1 & $3.5 \pm 1.2 \mathrm{a} \mathrm{A}$ & $3.4 \pm 0.9$ a A & $3.3 \pm 1.0 \mathrm{a} \mathrm{A}$ \\
\hline & 2 & $3.7 \pm 0.8$ a A & $3.6 \pm 1.1 \mathrm{a} \mathrm{A}$ & $3.5 \pm 1.0 \mathrm{a} \mathrm{A}$ \\
\hline & 3 & $3.5 \pm 1.2 \mathrm{a} \mathrm{A}$ & $3.5 \pm 1.4 \mathrm{a} \mathrm{A}$ & $2.8 \pm 1.2 \mathrm{a} \mathrm{A}$ \\
\hline & 4 & $3.7 \pm 0.6$ a A & $3.1 \pm 0.8$ a A & $3.2 \pm 1.2 \mathrm{a} \mathrm{A}$ \\
\hline \multirow{7}{*}{ שֶ } & & \multicolumn{3}{|c|}{ Nível de substituição (\%) } \\
\hline & Tempo (meses) & $\mathbf{0}$ & 25 & 50 \\
\hline & $\mathbf{0}$ & $4.1 \pm 1.0 \mathrm{a} \mathrm{A}$ & $4.1 \pm 1.0 \mathrm{a} \mathrm{A}$ & $3.0 \pm 0.6 \mathrm{~b} \mathrm{~A}$ \\
\hline & 1 & $4.1 \pm 1.0 \mathrm{a} \mathrm{A}$ & $3.2 \pm 1.2 \mathrm{~b} \mathrm{~A}$ & $3.0 \pm 1.2 \mathrm{~b} \mathrm{~A}$ \\
\hline & 2 & $4.3 \pm 0.6$ a A & $3.8 \pm 1.3 \mathrm{ab} A$ & $3.2 \pm 1.4 \mathrm{~b} \mathrm{~A}$ \\
\hline & 3 & $4.2 \pm 0.9 \mathrm{a} \mathrm{A}$ & $2.6 \pm 1.4 \mathrm{a} \mathrm{A}$ & $2.6 \pm 1.3 \mathrm{a} \mathrm{A}$ \\
\hline & 4 & $4.0 \pm 1.0 \mathrm{a} \mathrm{A}$ & $3.3 \pm 1.4 \mathrm{ab} \mathrm{A}$ & $2.5 \pm 1.0 \mathrm{~b} \mathrm{~A}$ \\
\hline \multirow{7}{*}{ 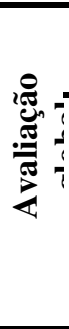 } & & \multicolumn{3}{|c|}{ Nível de substituição (\%) } \\
\hline & Tempo (meses) & $\begin{array}{c}\mathbf{0} \\
\end{array}$ & 25 & 50 \\
\hline & $\mathbf{0}$ & $4.2 \pm 0.7$ a A & $3.9 \pm 0.9 \mathrm{ab} \mathrm{A}$ & $3.4 \pm 0.4 \mathrm{~b} \mathrm{~A}$ \\
\hline & 1 & $3.6 \pm 1.1 \mathrm{a} \mathrm{A}$ & $3.2 \pm 0.8$ a A & $3.1 \pm 1.0 \mathrm{a} \mathrm{A}$ \\
\hline & 2 & $4.1 \pm 0.5 \mathrm{a} \mathrm{A}$ & $3.7 \pm 0.9 \mathrm{ab} \mathrm{A}$ & $3.2 \pm 0.9 \mathrm{~b} \mathrm{~A}$ \\
\hline & 3 & $4.0 \pm 0.8 \mathrm{a} \mathrm{A}$ & $3.1 \pm 1.1 \mathrm{~b} \mathrm{~A}$ & $2.9 \pm 0.9 \mathrm{~b} \mathrm{~A}$ \\
\hline & 4 & $3.6 \pm 0.7 \mathrm{a} \mathrm{A}$ & $3.3 \pm 1.0 \mathrm{ab} \mathrm{A}$ & $2.6 \pm 0.8 \mathrm{~b} \mathrm{~A}$ \\
\hline \multirow{7}{*}{$\begin{array}{l}\dot{\theta} \\
\dot{8} \\
\dot{\Xi} \\
\dot{\Xi} \\
\dot{0}\end{array}$} & & \multicolumn{3}{|c|}{ Nível de substituição (\%) } \\
\hline & Tempo (meses) & $\mathbf{0}$ & 25 & 50 \\
\hline & $\mathbf{0}$ & $43.60 \pm 2.07 \mathrm{a} \mathrm{AB}$ & $44.60 \pm 3.05 \mathrm{a} \mathrm{A}$ & $35.30 \pm 1.20 \mathrm{~b} \mathrm{~A}$ \\
\hline & 1 & $38.20 \pm 3.90 \mathrm{ab} B$ & $42.60 \pm 1.78 \mathrm{a} \mathrm{A}$ & $37.30 \pm 3.27 \mathrm{~b} \mathrm{~A}$ \\
\hline & 2 & $42.40 \pm 2.22 \mathrm{a} \mathrm{AB}$ & $44.50 \pm 4.24 \mathrm{a} \mathrm{A}$ & $34.80 \pm 2.17 \mathrm{~b} \mathrm{~A}$ \\
\hline & 3 & $44.50 \pm 2.92 \mathrm{a} \mathrm{A}$ & $46.90 \pm 3.36 \mathrm{a} \mathrm{A}$ & $34.10 \pm 3.29 \mathrm{~b} \mathrm{~A}$ \\
\hline & 4 & $43.30 \pm 3.77 \mathrm{a} \mathrm{AB}$ & $42.70 \pm 1.20 \mathrm{a} \mathrm{A}$ & $36.20 \pm 3.56 \mathrm{~b} \mathrm{~A}$ \\
\hline \multirow{7}{*}{ 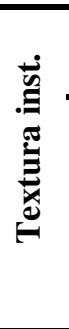 } & & \multicolumn{3}{|c|}{ Nível de substituição (\%) } \\
\hline & Tempo (meses) & $\begin{array}{c}\mathbf{0} \\
\end{array}$ & 25 & $\mathbf{5 0}$ \\
\hline & $\mathbf{0}$ & $1148.09 \pm 98.95 \mathrm{~b} \mathrm{~A}$ & $1187.34 \pm 92.26$ b B & $1503.14 \pm 223.74$ a B \\
\hline & 1 & $849.98 \pm 90.29$ с C & $1181.79 \pm 161.87$ b B & $1689.96 \pm 177.54 \mathrm{a} \mathrm{AB}$ \\
\hline & 2 & $831.80 \pm 116.64$ c C & $1336.72 \pm 112.90 \mathrm{~b} \mathrm{AB}$ & $1538.63 \pm 134.82 \mathrm{a} \mathrm{AB}$ \\
\hline & 3 & $1042.37 \pm 144.93 \mathrm{c} \mathrm{AB}$ & $1374.07 \pm 227.82 \mathrm{~b} \mathrm{AB}$ & $1742.57 \pm 169.64$ a A \\
\hline & 4 & $951.37 \pm 160.13$ c BC & $1416.53 \pm 137.26$ b A & $1190.33 \pm 158.13 \mathrm{a} \mathrm{C}$ \\
\hline
\end{tabular}

As amostras (média \pm desvio padrão) seguidas de mesmas letras minúsculas na linha não diferem ao nível de $5 \%$.

As amostras (média \pm desvio padrão) seguidas de mesmas letras maiúsculas na coluna não diferem ao nível de $5 \%$.

As letras minúsculas na LINHA testa se há diferenças significativas entre as amostras dentro de cada época

As letras maiúsculas na COLUNA testa se houve diferenças durante o período de estocagem para cada amostra 
De forma geral, das características avaliadas nas amostras de TPQE e TPQSE, o volume específico e a textura instrumental foram as que mais apresentaram variação devido ao efeito da substituição de queijo e estocagem.

A substituição de queijo ocasionou maior diferença significativa nos parâmetros avaliados no PTPQSE quando comparado com o PTPQE.

No PTPQE a substituição de queijo até $25 \%$ e a estocagem ocasionaram maior diferença significativa $(\mathrm{p}<0,05)$ no volume específico e textura instrumental com relação ao padrão. No entanto, o PTPQE com substituição e estocado durante 2 meses apresentou melhor nota no volume específico.

Segundo Oliveira et al. (2012) na forma em pó, o uso do soro de leite permite aumentar o volume dos pães e bolos.

Em termos de características sensoriais a formulação escaldada com $25 \%$ de substituição de queijo diferiu significativamente $(\mathrm{p}<0,05)$ da formulação padrão com 3 meses de estocagem apenas na avaliação global, no entanto, a formulação com substituição de queijo apresentou maior pontuação.

A substituição de queijo e o tempo de estocagem ocasionaram efeito significativo $(\mathrm{p}<0,05)$ em todas as características avaliadas no PTPQSE exceto com relação ao sabor.

Dentre as prováveis causas da maior variação nas características do PTPQSE quando comparado com o PTPQE, discutidas a seguir, podemos citar: função do queijo na formulação, as diferenças na composição do queijo quando comparado com a do CPS, as propriedades tecnológicas do CPS e as diferenças nas características dos dois processos tecnológicos utilizados no preparo das amostras.

O queijo além de contribuir para o aroma e o sabor típico dos produtos, tem um papel fundamental na estruturação da massa, auxilia na textura e confere melhor aspecto da casca do produto final (ZELAYA, 2000; PEREIRA et al., 2004), além de conferir uma maior maciez e uniformidade às células do miolo (JESUS, 1997). Essas propriedades estão relacionadas com a composição e as propriedades tecnológicas dos seus componentes.

Em trabalho de Minim et al., (2000) realizado com o objetivo de avaliar o efeito dos ingredientes nas propriedades sensoriais do pão de queijo escaldado foi observado que maior quantidade de queijo na formulação ocasionou aumento significativo $(\mathrm{p}<0,05)$ dos atributos cor, pontos de queijo, uniformidade, aroma e sabor de óleo. Nesse mesmo trabalho foi evidenciado através da Análise Descritiva Quantitativa que as características sensoriais das 7 formulações avaliadas mudaram significativamente $(\mathrm{p}<0,05)$ com a variação dos ingredientes utilizados nas formulações. Uma das formulações avaliou o efeito da quantidade de queijo adicionando (50 e 70\% 
g/100g de polvilho) de queijo minas padrão. Por outro lado, as alterações nas formulações não influenciaram significativamente $(\mathrm{p}<0,05)$ na aceitabilidade das sete formulações.

A composição do queijo e do CPS utilizados neste trabalho difere quanto ao tipo e quantidade de nutrientes. O queijo Minas padrão apresenta em média 48\% de umidade, 24\% de gordura e 23 a 25\% de proteína (PERRY, 2004). Já o ALACEN apresenta uma concentração proteica da ordem de $80 \%$. Além disso, o queijo é um concentrado proteico gorduroso no qual a proteína presente é basicamente a caseína.

As diferentes características tecnológicas da caseína e das proteínas do soro são mais uma causa dos resultados obtidos na análise estatística. A caseína é uma proteína micelar, classificada como uma fosfoproteína. Devido à presença de grupos fosfato concentrados em diferentes regiões das cadeias polipeptídicas apresenta caráter anfifílico. Além disso, a caseína é mais suscetível à proteólise e difunde-se mais rápida e fortemente em interfaces do que as proteínas do soro de leite.

Em virtude do alto teor de $\beta$-lactoglobulina (50\%) presente no soro bovino as propriedades dos CPS são na verdade às dessa proteína predominante. A $\beta$-lactoglobulina é capaz de ligar compostos hidrofóbicos e de formar gel, espuma e emulsificar. Acima de $70^{\circ} \mathrm{C}$ se desnatura com facilidade pela ação do calor o que não acontece com a caseína que é termorresistente (ANTUNES et al., 2003).

A proteína que se apresenta com o segundo maior teor no soro é a $\alpha$-lactoalbumina, com 13\%. Caracteristicamente esta proteína é a única capaz de se ligar ao cálcio (ANTUNES et al., 2003).

A capacidade das proteínas do soro de leite, quando em solução, de formar géis estáveis através do aquecimento é uma importante propriedade funcional já conhecida. Com o aumento da concentração proteica ocorre modificação da textura dos géis, resultando em aumento da firmeza e intensificando a retenção de água pela matriz (MANGINO, 1984).

Para o processo de gelatinização do CPS é necessária uma concentração mínima de proteínas que, à temperatura na faixa de 70 a $90^{\circ} \mathrm{C}$, pode variar entre $6-12 \%$, dependendo do $\mathrm{pH}$. Temperaturas elevadas favorecem a formação de géis mais firmes (ANTUNES et al., 2003). Conforme já citado, durante o assamento a temperatura no interior do pão de queijo atinge valores próximos a $75^{\circ} \mathrm{C}$.

Segundo SGARBIERI (2005) o conhecimento das diferenças estruturais e das propriedades físico-químicas entre as várias formas de caseína e as proteínas do soro é indispensável para a compreensão do comportamento tecnológico e funcional, nutritivo e fisiológico dessas proteínas, como parte de um sistema alimentício. No entanto, a falta de um conhecimento mais completo das estruturas da caseína e das proteínas do soro de leite e das suas alterações em diferentes condições de acidez $(\mathrm{pH})$, de concentrações salinas (força iônica) e de temperatura, torna difícil a 
interpretação de como as proteínas do leite interagem entre si e com outras espécies moleculares que compõem os alimentos e, dessa forma, dificulta explicar as variações observadas em suas propriedades físicas, tecnológicas, nutritivas e fisiológicas, em razão dos vários fatores presentes no processamento, no armazenamento e na distribuição dos alimentos para o consumo.

No processo de fabricação industrial de pão de queijo a etapa de escaldamento é substituída pelo amido pré-gelatinizado no processamento do PQSE e é bem provável que isto tenha uma relação com os resultados obtidos. Assim, a utilização de CPS afetou mais a qualidade do PTPQE do que a do PTPQSE.

O escaldamento é considerado chave na fabricação do pão de queijo por afetar a textura, o sabor e a aparência final do produto. Por sua vez, a mistura de ingredientes e a alta temperatura durante o escaldamento também são importantes na qualidade do produto. Sabe-se que durante o escaldamento ocorre a gelatinização do amido devido a modificações na estrutura interna dos grânulos, quando estes são aquecidos em presença de água. No caso do amido de mandioca a faixa de temperatura de gelatinização é de 58 a $70^{\circ} \mathrm{C}$ (PEREIRA, 1998).

Poucos trabalhos avaliaram o desempenho do amido de mandioca pré-gelatinizado na elaboração de PQSE em comparação com o PQE. Segundo Santos (2006), que avaliou o PQE e PQSE no desenvolvimento de um produto funcional adicionado de polidextrose e concentrado protéico de soja, a utilização de amido modificado é adequada, pois reduz o tempo de preparação dos pães de queijo sem interferir na qualidade final do produto.

No PQSE, as células de ar incorporadas durante a mistura dos ingredientes se expandem devido ao vapor de água liberado durante o assamento (PEREIRA, 1998). Já no PQE, a massa é aerada devido à incorporação de células de ar durante a mistura dos ingredientes e pelos lipídios durante o escaldamento.

No PQSE os grânulos de amido não são gelatinizados durante a mistura conforme acontece no processamento do PQE e é apenas utilizada temperatura acima da de gelatinização do amido de mandioca na etapa de assamento. Por isso, o amido modificado utilizado na elaboração do PQSE tem de ser pré-gelatinizado (ZAMBRANO et al., 2012).

A função do amido pré-gelatinizado é ligar água a frio necessária para a formação da pressão de vapor de água, criando o efeito de expansão do pão de queijo durante o forneamento. Essa água ligada hidrata as proteínas do sistema, indispensáveis para o desenvolvimento da resistência da rede formada, prevenindo assim o colapso da estrutura do produto após o forneamento (SANTOS, 2006).

\section{Conclusão}


Foi possível obter PTPQE estocado durante 2 meses utilizando ALACEN como substituto parcial $(25 \%)$ de queijo sem ocasionar diferenças significativas nas características sensoriais avaliadas e com melhor volume específico com relação ao padrão.

A adição de CPS e a estocagem ocasionaram diferença significativa $(\mathrm{p}<0,05)$ no PTPQSE em todas as características sensoriais exceto no sabor.

Das características avaliadas no PTPQE e PTPQSE o sabor e a textura instrumental foram as que apresentaram menor e maior variação significativa $(\mathrm{p}<0,05)$, respectivamente, devido ao efeito da adição de CPS como substituto de queijo e da estocagem.

\begin{abstract}
The objective of this study was to evaluate the effect of using whey protein concentrate (WPC) as a partial cheese substitute in a product like cheese bread (PLCB). The addition of WPC was conducted through sensory evaluation by appearance, crust appearance, texture, flavor and overall. The specific volume was also determined using the seed displacement method, and the texture using the TA-XT2i texturometer. The results were evaluated by the analysis of variance (ANOVA) and Tukey's test at the 5\% significance level, using the Statistical Analysis System, version 8.0 (The SAS Institute, Cary, N.C., USA). The substitution of cheese and storage time caused significant effect $(p<0.05)$ in all product like non-scalded cheese bread (PLNECB) parameters except to the flavor. It was possible to obtain a product like scalded cheese bread PLECB stored for 2 months using whey protein concentrate (WPC) as partial cheese replacement $(25 \%)$ without causing significant differences in sensory characteristics and best specific volume standard.
\end{abstract}

Key-words: Bakery products; industrial byproducts; $\beta$-lactoglobulin; $\alpha$-lactoalbumin; sensory evaluation.

\title{
Referências
}

ANTUNES, A.E.C.; MOTTA, E.M.P.; ANTUNES, A.J. Perfil de textura e capacidade de retenção de água de géis ácidos de concentrado proteico de soro de leite. Ciência e Tecnologia de Alimentos, Campinas, v. 23, p.183-189, 2003.

ANTUNES, J.A. Funcionalidade de proteínas de soro bovino. Barueri: Manole. 2003. 142p.

ANTUNES, A.E.C.; CAZETTO, T.F.; BOLINI, H.M.A. Iogurtes desnatados probióticos adicionados de concentrado proteico do soro de leite: perfil de textura, sinérese e análise sensorial. Alimentos e Nutrição, Araraquara, v. 15, n. 2, p. 107-114, 2004.

BENASSI, V.T.; WATANABE, E.; LOBO, A.R.; Produtos de panificação com conteúdo calórico reduzido. Boletim CEPPA, Curitiba, v.19, n.2, p.225-242, 2001.

BORGES, P. Z. (2000) Avaliação nutricional de concentrados proteicos obtidos de leite bovino. (83)f. Dissertação (Mestrado em Alimentos e Nutrição), Universidade Estadual de Campinas, Campinas-SP.

CLARETO, S. S.; LEE, N .D. ; PEREIRA, A. J. G. (2006). Influence of a protein concentrate used as a fat substitute on the quality of cheese bread. Brazilian Archives of Biology and Technology. Curitiba, v. 49, n. 6, p. 478-484, 2006.

ESTELLER, M.S.; LANNES, S.C.S.; Parâmetros complementares para fixação de identidade e qualidade de produtos panificados Ciência e Tecnologia de Alimentos, Campinas, v.25, n.4, p.802-806, 2005. 
INTERNATIONAL ORGANIZATION FOR STANDARDIZATION. Sensory Analysis - General Guidance for Selection, Training and Monitoring of Assessors: ISO 8565-1. Part 1: Selected assessors. Geneva, International Organization for Standardization, 1993. p.1-15.

JESUS, C.C. Contribuição para a caracterização físico-química e sensorial do pão de queijo. $1997.106 f$. Dissertação (Mestrado em Ciência de Alimentos) - Faculdade de Farmácia, Universidade Federal de Minas Gerais, Belo Horizonte, 1997.

MAISTRO, L.C. Aplicação de concentrados proteicos de soro de leite bovino em iogurtes. 1999 107f. Tese de Doutorado - Faculdade de Engenharia de Alimentos, Universidade Estadual de Campinas, 1999.

McMAHON, D.J. et al. Use of fat replacers in low fat mozzarella cheese. Journal of Dairy Science, Champaign, v.79, n.11, p.1911-1921, 1996.

MANGINO, M.E. Physicochemical aspects of whey protein functionality. Journal of Dairy Science, Champaign, v. 67, n. 11, p. 2711-2722, 1984.

MINIM, V. P. R. et al. Perfil sensorial e aceitabilidade de diferentes formulações de pão de queijo. Ciência e Tecnologia de Alimentos, Campinas, vol.20, n.2, p.154-159, 2000.

O'BRIEN, C.M. et al. Evaluation of the effects of fat replacers on the quality of wheat bread, Journal of Food Engineering, Oxford, v.56, n.2-3, p.265-267, 2003.

OLIVEIRA, D.F.; BRAVO, C. E. C.; TONIAL, I.V. Soro de leite: um subproduto valioso. Revista do Instituto de Laticínios "Cândido Tostes", Juiz de Fora, v. 67, n. 385, p.64-71, 2012.

PEREIRA, A.J.G. Fatores que afetam a qualidade do pão de queijo. Belo Horizonte: CETEC, 1998. 52p.

PEREIRA, J. et al. Função dos ingredientes na consistência da massa e nas características do pão de queijo. Ciência e Tecnologia de Alimentos., Campinas, 24(4), 494-550. 2004.

PERRY, K. S. P. Queijos: aspectos químicos, bioquímicos e microbiológicos. Química Nova, São Paulo, vol.27, n.2, p. 293-300, 2004.

PIROZI, M.R.; CANAVESI, E. Como montar uma pequena fábrica de pão de queijo. Viçosa: CPT, 1998. 42p.

SANDOVAL-CASTILLA, O. et al. Microstructure and texture of yogurt as influenced by fat replacers. International Dairy Journal, Oxford, v.14, n.2, p.151-159, 2004.

SANTOS, J.R.U. Desenvolvimento de pão de queijo funcional pela incorporação de isolado proteico de soja e polidextrose. 2006. 107f. Dissertação (Mestrado em Tecnologia de Alimentos)-Faculdade de Engenharia de Alimentos, Universidade Estadual de Campinas, 2006.

SGARBIERI, V.C. Revisão: propriedades estruturais e físico-químicas das proteínas do leite. Brazilian Journal of Food Technology, Campinas, v.8, n.1, p. 43-56, 2005.

SIVIERI, K.; OLIVEIRA, M. N. Shelf-life evaluation of latic beverages added with fat with mimetics (Litesse and Dairy-Lo). Ciência e Tecnologia de Alimentos, Campinas, v. 22, n.1, p. 24-31, 2002.

STABLE MICRO SYSTEMS. (1997). User manual. Texture analyser modelo TA-XT2i, Vienna Court, Version 6.10 e $7.10,87$ p.

YAZICI, F.; AKGUN, A. Effect of some protein based fat replacers on physical, chemical, textural, and sensory properties of strained yoghurt, Journal of Food Engineering, Oxford, v. 62, n.3, p.245-254, 2004.

ZAMBRANO, F.; SILVA, M. C.; ORMENESE, R. C. S. C. Avaliação preliminar da utilização de concentrado proteico de soro como substituto de gordura e queijo em pão de queijo. In: SIMPÓSIO LATINO AMERICANO DE CIÊNCIA E TECNOlOGIA DE ALIMENTOS - SLACA, 8, 2009, Campinas, Anais.... Campinas: Universidade Estadual de Campinas, 2009.

ZAMBRANO, F; SILVA, M.C.; ORMENESE, R.C.C.; YOTSUYANAGI, K. Concentrado proteico de soro como substituto de gordura em pão de queijo. Brazilian Journal Food Technology, Campinas, v. 15, n. 3, p. $244-252$, 2012. 
ZELAYA, M.P. (2000). Tecnología y química de almidones nativos y modificados. In: PIZZINATTO, A; ORMENESE, R. de C.S.C. Seminário pão de queijo: ingredientes, formulação e processo. Campinas. Governo do Estado de São Paulo/Secretaria de Agricultura e Abastecimento/Agência Paulista de Tecnologia dos Agronegócios/Instituto de Tecnologia de Alimentos/Centro de Tecnologia de Cereais e Chocolate. 2000. p.15-28. 